\title{
The First 100 Cases of Two Innovations Combined: Video-Assisted Minimally Invasive Aortic Valve Replacement Through Right Anterior Mini- Thoracotomy Using a Novel Aortic Prosthesis
}

\author{
Ali El-Sayed Ahmad · Saad Salamate · Mohamed Amer • \\ Sami Sirat · Ömur Akhavuz · Farhad Bakhtiary
}

Received: February 17, 2021 / Accepted: March 10, 2021 / Published online: March 31, 2021

(C) The Author(s) 2021

\section{ABSTRACT}

Introduction: Aortic valve replacement (AVR) via right anterior mini-thoracotomy (RAMT) is less traumatic than via other surgical routes; using a novel aortic valve may confer long-term resistance against valve deterioration, and thus be useful in younger, more active patients. Here we aim to validate using the INSPIRIS RESILIA valve with minimally invasive RAMT.

Methods: Between April 2017 and June 2019, 100 patients underwent video-assisted minimally invasive AVR by RAMT, using the INSPIRIS RESILIA aortic valve. Cannulation for cardiopulmonary bypass (CPB) was through femoral vessels. Clinical data were prospectively entered into our institutional database.

Results: Cardiopulmonary bypass (CPB) and cross-clamping times were $79 \pm 38$ and $41 \pm 17 \mathrm{~min}$. Surgical access was successful in $100 \%$ of cases. There were no cases of intraoperative mortality, 30-day mortality, cerebrovascular events, rethoracotomy for bleeding, valve- related reoperation, right internal mammary artery injury, or conversion to sternotomy. Intensive care and hospital stays were $2 \pm 1$ and $6 \pm 3$ days, respectively. One patient had a pacemaker fitted. Postoperative dialysis was necessary in one patient. Trace to mild aortic valve regurgitation occurred in two patients. No structural valve deterioration (SVD) and paravalvular leak were seen. At 1-year follow-up mean effective orifice area (EOA) was $1.8 \pm$ $0.1 \mathrm{~cm}^{2}$, peak gradient was $22.1 \pm 3.1 \mathrm{mmHg}$, and mean gradient was $11.5 \pm 2.3 \mathrm{mmHg}$.

Conclusion: Our preliminary experience suggests that RAMT for AVR using the INSPIRIS RESILIA aortic valve is safe, effective, and reproducible. Larger studies are needed to evaluate the long-term efficacy and durability of this new valve.

Keywords: Minimally invasive valve surgery; Aortic valve replacement; INSPIRIS RESILIA aortic valve

A. El-Sayed Ahmad ( $₫)$. S. Salamate - M. Amer .

S. Sirat · Ö. Akhavuz · F. Bakhtiary

Division of Cardiac Surgery, Heart Centre Siegburg-

Wuppertal, University Witten-Herdecke, Siegburg,

Germany

e-mail: ali.assayed@gmail.com 


\section{Key Summary Points}

Over the last two decades, minimally invasive aortic valve replacement (MIVAR) has demonstrated good safety and efficacy compared with both conventional and transcatheter aortic valve implantation (TAVI).

The use of video-assistance technology in minimally invasive surgery through right anterior mini-thoracotomy (RAMT) reduces operative times and improves outcomes.

To improve the durability of bioprostheses by reducing structural valve deterioration (SVD), Edwards Lifesciences has launched the INSPIRIS RESILIA bioprosthetic valve, incorporating novel RESILIA tissue preservation technology.

To optimize the short- and long-term outcomes of surgical aortic valve replacement, the INSPIRIS RESILIA valve was implanted via minimally invasive, video-assisted RAMT.

Primary safety and efficacy data at 1 year for the first 100 patients show that this procedure demonstrated $100 \%$ operative success with low rates of postoperative complications. Valve hemodynamic performance at 1 year was excellent with no paravalvular leak and no observed SVD.

These preliminary data suggest that the use of the INSPIRIS RESILIA valve with RAMT is safe, effective, and reproducible.

\section{DIGITAL FEATURES}

This article is published with digital features, including a summary slide, to facilitate understanding of the article. To view digital features for this article go to https://doi.org/10.6084/ m9.figshare.14185076.

\section{INTRODUCTION}

During the last two decades, minimally invasive aortic valve replacement (MIAVR) has demonstrated increasing success in terms of safety and efficacy compared with both conventional sternotomy (CS) [1] and transcatheter aortic valve implantation (TAVI) [2].

Although right anterior mini-thoracotomy (RAMT) outcomes depend on mastering MIAVR techniques, they benefit both from advancements in cardiopulmonary bypass (CPB) techniques and from the utilization of videothoracoscopic assistance; the latter adds considerable benefit to performance and procedural safety, bringing a reduction in cross-clamp times, CPB times, and ventilator support, and shorter intensive care and total hospital time [3-5].

To improve the durability of current bioprosthetic valves by potentially reducing structural valve deterioration (SVD), in 2016 Edwards Lifesciences launched a new generation of bioprosthetic valve-the INSPIRIS RESILIA (Edwards Lifesciences, Irvine, CA 92614, USA), which has been approved for use in Europe and the USA since 2017. The valve (model 11500A) is a stented, trileaflet valve composed of bovine pericardial tissue mounted underneath a flexible frame. It shares a similar design to the Carpentier-Edwards PERIMOUNT valve in terms of core stent construction and leaflet design [6]. The bovine tissue within the valve incorporates a novel preservation technology called RESILIA, which blocks residual aldehyde groups known to bind to calcium, and preserves the tissue with glycerol prior to surgical implantation, enabling dry storage of the valve [6]. A randomized controlled trial (RCT) animal study of mitral valve implants demonstrated a significantly reduced calcium build-up (- 72\%) compared with traditional valve tissue after 8 months in juvenile sheep [7], raising the prospect that this reduced calcification could potentially improve the longevity of the valve. RESILIA tissue has since been evaluated in two large clinical studies with 
a combined total of over 800 patients across Europe and the USA. Both intermediate-term and final outcomes of these studies demonstrated safety and sustained hemodynamic performance up to 5 years of follow-up, with no SVD [8-11]. Furthermore, INSPIRIS RESILIA valve design promises increased tissue longevity, thus reducing the need for repeat surgery, along with the potential for effective future valve-in-valve (VIV) procedures thanks to specific valve design modifications [8].

In an attempt to further optimize the shortand long-term outcomes of surgical aortic valve replacement (SAVR), our institution combined these two surgical innovations: performing MIAVR with video-assisted RAMT and replacing the damaged valve with this novel prosthesis.

The aim of the current study was to analyze and present our 1-year outcomes for the first 100 such cases.

\section{METHODS}

\section{Study Design and Data Source}

This is a retrospective study of prospectively collected data from 100 patients with aortic valve disease (AVD) who underwent isolated aortic valve replacement with INSPIRIS RESILIA valve prosthesis via video-assisted RAMT in the Division of Cardiac Surgery, Heart Centre Siegburg-Wuppertal, University Witten-Herdecke (Germany) between April 2017 and June 2019. The data was collected from the electronic medical records and patient registry at our institution and include medical history, physical assessments, perioperative parameters, and discharge parameters (including electrocardiogram (ECG), laboratory results, and transthoracic/transesophageal echocardiography (TTE/ TEE)).

All patients with AVD were included in this study except for pregnant women. The decision of valve type was made between patient and surgeon on the basis of many criteria such as lifestyle choice, desire for pregnancy, and/or contraindication for anticoagulation therapy.

The study was approved by the ethics committee of the Medical Association of North
Rhine, Germany (Ifd. Nr. 2019201/2019), and individual patient consent for the study was waived. The study was performed in accordance with the declaration of Helsinki 1964 and its later amendments.

The primary endpoint was 30-day mortality. Secondary endpoints were incidence of valverelated complications, hemodynamic performance of the valve, operative times, and duration of hospitalization.

\section{The Valve}

The INSPIRIS RESILIA aortic valve is a stented trileaflet valve comprised of RESILIA bovine pericardial tissue that is mounted on a flexible frame. The RESILIA bovine tissue within the valve incorporates a novel preservation technology, which blocks residual aldehyde groups known to bind to calcium, and preserves the tissue with glycerol prior to surgical implantation, enabling dry storage of the valve. The frame is designed to be compliant at the orifice as well as at the commissures. The wireform is made from cobalt-chromium alloy to improve spring efficiency and fatigue-resistance. Additionally, the valve is equipped with VFit technology, which includes fluoroscopically visible size markers and an expansion zone, to facilitate future VIV procedures [6].

\section{Patients}

The mean age of patients was $56 \pm 9$ years; 61 patients $(61 \%)$ were male, and $61(61 \%)$ were in New York Heart Association (NYHA) class I/II. Degenerative aortic valve stenosis was diagnosed in 93 patients (93\%), aortic valve regurgitation in five patients (5\%), and aortic valve endocarditis in two patients (2\%). Elective, redo, and emergency surgery were performed in 97 patients $(97 \%)$, six patients $(6 \%)$, and three patients $(3 \%)$, respectively. The size of the valves implanted ranged from 19 to $29 \mathrm{~mm}$, as shown in Table 1 . Relevant clinical characteristics of our patients are summarized in Table 2 . Clinical data were prospectively entered into our institutional database. 
Table 1 Valve size distribution

\begin{tabular}{ll}
\hline Valve size & $\boldsymbol{N}(\%)$ \\
\hline $19 \mathrm{~mm}$ & $2(2)$ \\
$21 \mathrm{~mm}$ & $15(15)$ \\
$23 \mathrm{~mm}$ & $42(42)$ \\
$25 \mathrm{~mm}$ & $26(26)$ \\
$27 \mathrm{~mm}$ & $14(14)$ \\
$29 \mathrm{~mm}$ & $1(1)$ \\
\hline
\end{tabular}

\section{Operative techniques}

All procedures were performed under conventional general anesthesia. The patient was placed in a supine position, and two defibrillator pads were placed across the chest wall. After heparin administration, cannulation for $\mathrm{CPB}$ was achieved through the common femoral vessels. Ultrasound sonography was peri- and postoperatively used to assess the femoral vessels. Surgical femoral access was performed in 63 patients (63\%); the remaining 37 patients (37\%) underwent percutaneous femoral artery access, and closure with the MANTA ${ }^{\mathrm{TM}}$ vascular closure device (VCD) (Essential Medical Inc., Malvern, Pennsylvania, USA).

RAMT was performed $2 \mathrm{~cm}$ lateral to the sternal border to the level of second or third intercostal space (ICS) through a 3 to $5 \mathrm{~cm}$ skin incision (Fig. 1a). After dividing the intercostal tissue without resection or dislocation of the rib or cartilage transection, and preserving the right internal thoracic artery and vein, the pleural space was accessed laterally and a soft tissue retractor (Valve Gate ${ }^{\mathrm{TM}}$ Soft Tissue Protector, Geister, Germany) was placed to optimize the exposure.

The pericardium was opened $5 \mathrm{~cm}$ above the phrenic nerve and stay sutures placed to obtain an optimal position and view of the aorta and aortic root. Two small incisions of $5 \mathrm{~mm}$ were made in the ICS above the mini-thoracotomy for placement of the 3D camera (Aesculap EinsteinVision, Tuttlingen, Germany) and Chitwood $\AA$ aortic clamp (Scanlan International, Inc, St Paul, MN, USA). $\mathrm{CO}_{2}$ was infused at a rate
Table 2 Patient characteristics

\begin{tabular}{ll}
\hline Characteristic & $\boldsymbol{N}(\%)$ \\
\hline Mean age (years \pm SD) & $56 \pm 9$ \\
Male & $61(61)$ \\
Mean BMI $\left(\mathrm{kg} / \mathrm{m}^{2}\right)$ & $24.2 \pm 4.4$ \\
Diabetes & $36(36)$ \\
Peripheral vascular disease & $9(9)$ \\
Dyslipidemia & $29(29)$ \\
Hypertension & $73(73)$ \\
Coronary artery disease & $12(12)$ \\
Stroke & $2(2)$ \\
Chronic obstructive pulmonary disease & $19(19)$ \\
Chronic kidney disease & $11(11)$ \\
Mean Logistic EuroSCORE (\%) & $5.8 \pm 6.4$ \\
NYHA class I/II & $61(61)$ \\
Pacemaker & $1(1)$ \\
Degenerative aortic valve stenosis & $93(93)$ \\
Aortic valve regurgitation & $5(5)$ \\
Aortic valve endocarditis & $2(2)$ \\
Atrial fibrillation & $15(15$ \\
\hline
\end{tabular}

$B M I$ body mass index, EuroSCORE European system for cardiac operative risk evaluation, NYHA New York Heart Association

of $3 \mathrm{l} / \mathrm{min}$ through the camera port. A long cardioplegia catheter (Medtronic DLP 9F, Ref 10012) secured by a 3.0 polypropylene pursestring was inserted into the ascending aorta. The left ventricular vent was placed through the right upper pulmonary vein and secured by a 3.0 polypropylene purse-string.

The ascending aorta was occluded with a Chitwood clamp, and crystalloid cardioplegia (Custodiol; Koehler Chemi, Alsbach-Haenlien, Germany) was administered antegrade into the aortic root. In cases of aortic regurgitation, cardioplegia was administered directly into the coronary ostia after opening the ascending aorta. A normothermic CPB was performed in all patients. Once the heart was arrested and 


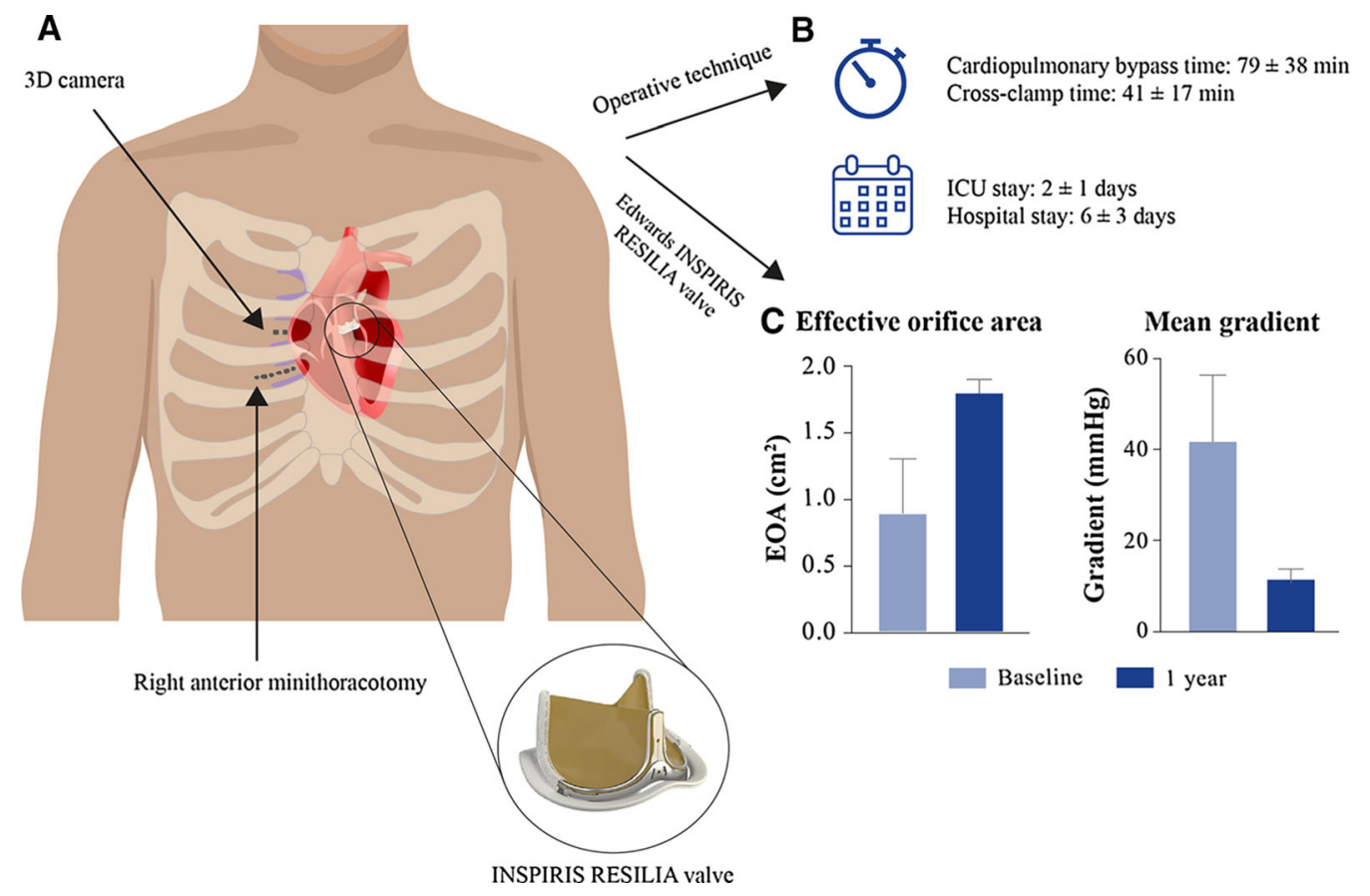

Fig. 1 Outcomes following implantation of INSPIRIS RESILIA aortic valve via video-assisted right anterior minithoracotomy. a Access for RAMT and 3D camera; b operative times achieved using video-assisted RAMT;

emptied, a transverse incision of the ascending aorta was performed. Thereafter, the native aortic valve was totally excised, and residual calcium debrided from the annulus. The annulus was sized, and annular sutures placed. The INSPIRIS RESILIA aortic valve was inserted and secured in the aortic annulus using automated suturing with $\operatorname{Cor}-\operatorname{Knot}{ }^{\circledR}$ (Cor-Knot ${ }^{\circledR}$, LSI Solutions, USA). The aortotomy was closed in two layers with 4.0 Prolene and the heart deaired thorough the aortic and left ventricular vents. Ventricular pacing wires were placed before removing the cross-clamp. After declamping of the aorta and $\mathrm{CPB}$ weaning, protamine was administered at a $1: 1$ ratio to heparin. Intraoperative TEE was performed to assess the implanted prosthesis. A drain was placed through the cross-clamp incision site, the ribs were secured with two FiberWires (Arthrex; Naples, FL, USA), and intercostal nerve blocks were performed with bupivacaine $(0.25 \%)$. The wound was then closed in layers. c hemodynamic outcomes for the INSPIRIS RESILIA aortic valve. EOA effective orifice area, ICU intensive care unit

Arterial and venous decannulation was performed. For cases of surgical access, soft tissue and skin closure was performed with a resorbable intracutaneous suture; for percutaneous access, the MANTA ${ }^{\mathrm{TM}}$ system was used for femoral artery closure followed by a resorbable intracutaneous suture to close the skin incision.

\section{Statistical Analysis and Follow-up}

All perioperative data were collected prospectively. Data are presented as mean \pm SD. Categorical variables are expressed as percentages. All statistical analyses were performed with StatView (version 5.0) for Windows software (SAS Institute, Inc, Cary, NC). Follow-up for discharged patients took place in our outpatient clinic or by contacting the cardiologist by mail or telephone during a 2-month closing interval ending in February 2020 and was 100\% complete. 
Table 3 Operative data

\begin{tabular}{ll}
\hline Variable & $N(\%)$ \\
\hline Surgical access via RAMT & $100(100)$ \\
Conversion to sternotomy & $0(0)$ \\
Surgical femoral access & $63(63)$ \\
Percutaneous femoral access & $37(37)$ \\
Elective surgery & $97(97)$ \\
Redo surgery & $6(6)$ \\
Emergent surgery & $3(3)$ \\
CPB time & $79 \pm 38$ min \\
Cross-clamp time & $41 \pm 17$ min \\
\hline$C P B$ cardiopulmonary bypass, RAMT right anterior mini- \\
thoracotomy
\end{tabular}

\section{RESULTS}

\section{Operative Outcomes}

Operative data are shown in Table 3 . The technical success rate was $100 \%$, with no patients requiring conversion to full sternotomy. The surgery was performed electively in 97 patients (97\%). CPB and cross-clamping times were $79 \pm 38 \mathrm{~min}$ and $41 \pm 17 \mathrm{~min}$, respectively (Fig. 1b).

Intraoperative mortality, 30-day mortality, cerebrovascular events, rethoracotomy for bleeding, valve-related reoperation, right internal mammary artery (RIMA) injury, and conversion to sternotomy were all zero. No injury of phrenic nerve was noted.

Surgical femoral access was performed in 63 patients $(63 \%)$. Of these patients, two $(2.0 \%)$ developed wound infections in the groin and one $(1.0 \%)$ developed a femoral lymphatic fistula. In the remaining 37 patients (37\%) who received percutaneous femoral access, no cases of infection, vascular injury, malperfusion, compartment syndrome, lymphatic fistula, or conversion to surgical closure were noted (Table 4).
Table 4 Periprocedural outcomes

\begin{tabular}{ll}
\hline Variable & $\boldsymbol{N}(\%)$ \\
\hline Technical success & $100(100)$ \\
Intraoperative mortality & $0(0)$ \\
30-day mortality & $0(0)$ \\
Intensive care stay & $2 \pm 1$ days \\
Hospital stay & $6 \pm 3$ days \\
Cerebrovascular event & $0(0)$ \\
New postoperative dialysis & $1(1)$ \\
Postoperative onset of AF & $24(24)$ \\
Vascular dissection, perforation, or & $0(0)$ \\
obstruction & \\
Life-threatening/disabling bleeding & $0(0)$ \\
Rethoracotomy for bleeding & $0(0)$ \\
RIMA injury & $0(0)$ \\
Wound healing disorders & $1(1)$ \\
SVD & $0(0)$ \\
Paravalvular leak & $0(0)$ \\
Valve-related reoperation & $0(0)$ \\
Conversion to surgical closure & $0(0)$ \\
Wound infection in the groin & $2(2)$ \\
Hematoma in the groin & $0(0)$ \\
Femoral AV fistula & $0(0)$ \\
Femoral pseudo-aneurysm & $0(0)$ \\
Femoral lymphatic fistula & $1(1)$ \\
Femoral nerve injury & $0(0)$ \\
Occlusion or flow limiting of low extremity & $0(0)$ \\
peripheral artery & \\
\hline$A F$ & $R I M A$ \\
\hline
\end{tabular}

$A F$ atrial fibrillation $A V$ atrioventricular, RIMA right internal mammary artery, $S V D$ structural valve deterioration

\section{Early and Late Morbidity and Mortality}

Intensive care unit (ICU) stay and hospital stay were $2 \pm 1$ days and $6 \pm 3$ days, respectively (Fig. 1b). New postoperative dialysis was 
necessary in one patient (1.0\%). New onset of atrial fibrillation (AF) was observed in 24 patients $(24 \%)$. A pacemaker was implanted in one patient $(1.0 \%)$ because of an irreversible third-degree atrioventricular block (AVB). One patient (1.0\%) developed a superficial thoracic wound infection and was treated conservatively.

No SVD, paravalvular leak, valve endocarditis, or valve-related thrombosis were seen in early and late postoperative follow-up. Trace to mild transvalvular aortic regurgitation was observed in two patients at discharge and at 1-year follow-up.

\section{Hemodynamic Outcomes}

At discharge, 6 months, and 1 year, mean effective orifice area (EOA) was $2.0 \pm 0.2 \mathrm{~cm}^{2}$, $1.9 \pm 0.2 \mathrm{~cm}^{2}$, and $1.8 \pm 0.1 \mathrm{~cm}^{2}$, respectively; peak gradients were $20.8 \pm 4.3 \mathrm{mmHg}$, $21.1 \pm 4.0 \mathrm{mmHg}, \quad$ and $22.1 \pm 3.1 \mathrm{mmHg}$, respectively; and mean gradients were $10.6 \pm 2.6 \mathrm{mmHg}, \quad 10.9 \pm 2.5 \mathrm{mmHg}, \quad$ and $11.5 \pm 2.3 \mathrm{mmHg}$, respectively (Fig. 1c).
Follow-up data for TTE, according to the valve size, at discharge, 6 months, and 1 year are shown in Table 5.

\section{DISCUSSION}

Since the first description in 1993, MIAVR via RAMT has drawn increasing confidence from surgeons-showing superiority over CS, with a lower transfusion rate, reduced duration of mechanical ventilation, and shorter ICU and hospital length of stay [3-5]. Importantly, and compared with other MIAVR accesses, RAMT has demonstrated lower morbidity and mortality, lower risk of postoperative impaired respiratory function and blood loss, less postoperative pain, and a quicker return to the normal productive lives of the patients $[2,12-14]$. The superiority of RAMT over other MIAVR accesses and CS also suggests superiority of RAMT over TAVI. In contrast to TAVI, RAMT enables surgeons to remove the underlying pathology, i.e., the calcified aortic valve, and to exactly size and implant a suitable valve

Table 5 Transthoracic echocardiographic data

\begin{tabular}{cllllllll}
\hline Variable & $\begin{array}{l}\text { Follow- } \\
\text { up }\end{array}$ & $\begin{array}{l}\text { All valve } \\
\text { sizes }\end{array}$ & $\mathbf{1 9} \mathbf{~ m m}$ & $\mathbf{2 1} \mathbf{~ m m}$ & $\mathbf{2 3} \mathbf{~ m m}$ & $\mathbf{2 5} \mathbf{~ m m}$ & $\mathbf{2 7} \mathbf{~ m m}$ & $\mathbf{2 9} \mathbf{~ m m}$ \\
\hline $\begin{array}{c}\text { EOA } \\
\left(\mathrm{cm}^{2}\right)\end{array}$ & Baseline & $0.9 \pm 0.4$ & $0.7 \pm 0.1$ & $0.7 \pm 0.3$ & $0.8 \pm 0.3$ & $1.4 \pm 1.3$ & $1.2 \pm 0.5$ & $1.1 \pm 0.0$ \\
& Discharge & $2.0 \pm 0.2$ & $1.5 \pm 0.1$ & $1.8 \pm 0.2$ & $2.0 \pm 0.2$ & $2.2 \pm 0.4$ & $2.3 \pm 0.2$ & $2.4 \pm 0.0$ \\
& 6 months & $1.9 \pm 0.2$ & $1.4 \pm 0.0$ & $1.8 \pm 0.4$ & $1.9 \pm 0.5$ & $2.1 \pm 0.2$ & $2.2 \pm 0.4$ & $2.4 \pm 0.0$ \\
& 1 year & $1.8 \pm 0.1$ & $1.4 \pm 0.0$ & $1.7 \pm 0.2$ & $1.8 \pm 0.1$ & $2.0 \pm 0.3$ & $2.1 \pm 0.2$ & $2.3 \pm 0.0$ \\
Peak & Baseline & $71.3 \pm 22.1$ & $79.4 \pm 2.1$ & $78.2 \pm 31.5$ & $75.3 \pm 32.1$ & $69.3 \pm 5.8$ & $63.7 \pm 29.9$ & $65.3 \pm 0.0$ \\
gradient & Discharge & $20.8 \pm 4.3$ & $26.4 \pm 1.1$ & $24.5 \pm 8.3$ & $20.1 \pm 4.1$ & $18.8 \pm 6.3$ & $16.6 \pm 5.7$ & $18.8 \pm 0.0$ \\
$($ mmHg) & 6 months & $21.1 \pm 4.0$ & $27.0 \pm 0.9$ & $24.8 \pm 9.2$ & $20.1 \pm 3.8$ & $18.5 \pm 5.7$ & $17.1 \pm 4.9$ & $19.1 \pm 0.0$ \\
& 1 year & $22.1 \pm 3.1$ & $28.3 \pm 1.0$ & $25.7 \pm 3.2$ & $22.1 \pm 5.6$ & $19.2 \pm 5.1$ & $17.3 \pm 4.1$ & $20.2 \pm 0.0$ \\
Mean & Baseline & $42.1 \pm 14.0$ & $45.4 \pm 2.1$ & $51.4 \pm 23.2$ & $50.4 \pm 18.3$ & $41.3 \pm 15.9$ & $32.9 \pm 24.8$ & $31.2 \pm 0.0$ \\
gradient & Discharge & $10.6 \pm 2.6$ & $12.1 \pm 1.7$ & $12.9 \pm 4.9$ & $10.2 \pm 2.3$ & $10.1 \pm 3.2$ & $8.4 \pm 3.4$ & $10.3 \pm 0.0$ \\
$(\mathrm{mmHg})$ & 6 months & $10.9 \pm 2.5$ & $12.1 \pm 1.5$ & $13.2 \pm 3.6$ & $10.7 \pm 3.8$ & $11.2 \pm 4.3$ & $8.3 \pm 2.1$ & $10.4 \pm 0.0$ \\
& 1 year & $11.5 \pm 2.3$ & $12.6 \pm 1.5$ & $14.1 \pm 5.7$ & $11.3 \pm 1.2$ & $11.4 \pm 2.8$ & $8.9 \pm 2.7$ & $11.2 \pm 0.0$ \\
\hline
\end{tabular}

$E O A$ effective orifice area 
prostheses under direct vision. This results in better outcomes regarding postoperative paravalvular leak, permanent pacemaker implantation, vascular complications, and cerebrovascular events [2, 15-17]. Another recent innovation-RESILIA tissue-has shown in an RCT significantly reduced tissue calcification $(-72 \%)$ at 8 months after implantation in a juvenile sheep model in the mitral position. In two multicenter clinical studies, the European Feasibility Study and COMMENCE, safety and hemodynamic performance were demonstrated up to 5 years after implantation in a relatively young group of around 800 patients with no SVD $[6,7]$. The RESILIENCE multicenter trial [18] is currently enrolling up to 250 patients younger than 65 years of age and with a minimum of 5 years since SAVR. It aims to provide a thorough description of SVD stages, and establish the long-term durability of RESILIA tissue valves up to 11 years of follow-up. Finally, two large real-world multicenter registries, INDURE (NCT03666741) [19] and IMPACT (NCT04053088) enrolling 400 and 600 patients, respectively, will assess the performance of the INSPIRIS RESILIA prosthesis in young patients less than 60 years of age and in patients with comorbidities.

Combining RAMT, an elegant minimally invasive technique, using this novel prosthesis has the potential to elevate SAVR patient outcomes to a next promising level, with the aim to (1) reduce mortality and morbidity while improving cosmetic and rehabilitation results, (2) to extend valve performance further especially in younger patients, allowing for potentially simpler decision-making when it comes to reintervention strategy owing to valve stent design characteristics. If these goals can be achieved, this would represent a significant evolution in SAVR, with maximum benefit for patients-the outcome that both cardiac surgeons and patients have been looking for. Our early outcome data were very satisfactory and encouraging, showing an absence of intraoperative and 30-day mortality, cerebrovascular events, rethoracotomy for bleeding, SVD, paravalvular leak, and valve-related thrombosis, with short ICU and hospital stay and satisfactory hemodynamic performance of the valve prosthesis, comparable to that of other bioprosthetic valves. Apart from the development of transient AF in 24 patients (24\%), there were no relevant postoperative complications.

Although the current American College of Cardiology/American Heart Association (AHA/ ACC) and European Society of Cardiology/ European Association for Cardio-Thoracic Surgery (ESC/ EACTS) guidelines recommend which type of aortic valve prosthesis should be used according to age and pre-existing conditions, the choice of prosthesis type remains a widely debated topic in aortic valve surgery [20-22]. It is widely known that mechanical prostheses are associated with a risk of thrombosis, or bleeding due to lifelong anticoagulation, while biological valves are associated with risks of SVD and subsequent reoperation especially in younger patients $[23,24]$. Therefore, in order to improve outcomes, surgeons are embracing minimally invasive techniques and industries are improving valve technologies to become suitable for all patients.

Still today durability of bioprostheses is a debated theme, especially in young patients and in patients with predisposing factors for SVD. In fact, in recently published studies a significant difference in SVD was reported across various valve models even at short-term follow-up [25-27]; thus, the concept of durability should be tailored to patients' profiles and to the type of prostheses.

However, long-term data from several studies based on the widely used Carpentier-Edwards PERIMOUNT aortic valve demonstrate low rates of valve-related events and SVD up to 20 years, especially in patients aged over 60 years [28]. In younger age groups, although the expected valve durability was still 17.6 years, longevity is influenced by age and some patients might require reintervention [29]. Thus, it is hoped that the INSPIRIS RESILIA valve could potentially extend the long-term results of its predecessor as well as allow for an easier valve reintervention strategy owing to its design modifications.

In our cohort, in which $83 \%$ patients were aged 65 years or younger, and $62 \%$ were below 60 years, no SVD or valve-related complications were noted during the 1-year follow-up, and 
hemodynamic data were similar to those observed in the previous studies. Despite the increased risk of SVD in patients under 65 years of age with a biological valve [30, 31], we believe that younger patients can significantly benefit from biological valves owing to the various reasons cited below. This has led to an increase in the use of biological valves, especially the novel INSPIRIS RESILIA aortic valve, in our institution.

1. The 2020 AHA/ACC guidelines lowered the age recommendations below which a mechanical valve is indicated, from 60 to 50 years; the guidelines also now state that patient preference should be taken into account when deciding on prosthesis type [21].

2. The choice of biological valve enables patients to avoid lifelong anticoagulation and its related severe bleeding complications [23].

3. Several studies demonstrate that the associated low mortality risk of redo surgery versus the increased risk of hemorrhage secondary to anticoagulation makes the option to use the bioprosthetic valve acceptable for younger patients [32-34]. Moreover, Milewski et al. reported that the choice of mechanical versus biologic/bioprosthetic valve does not affect the freedom from reoperation or survival rates in young patients under 30 years of age during midto long-term follow-up [35].

4. Data at 20 years, with a low rate of valverelated events and SVD associated with the Carpentier-Edwards PERIMOUNT bioprosthetic valve $[28,29]$, as well as the reduction in tissue calcification and significant improvement in hemodynamic performance shown by the preliminary results of RESILIA tissue studies [6-10], indicate that this new-generation RESILIA prosthesis will deliver much better results regarding hemodynamic performance and durability.

5. The new generation of bioprosthetic aortic valves enables a catheter-based VIV redo option when a previous prosthesis fails.

All previous cited reasons motivate us to implant more the new aortic valve prosthesis even in young patients. There is no doubt that larger size studies with long-term follow-up (over 20 years) are needed to evaluate the longterm efficacy and durability of the new INSPIRIS RESILIA aortic valve. In our opinion, shifting the indication age from 65 to 55 year and lower for biological valve lead to a great step in the evolution of aortic valve surgery and enables us to track and evaluate primarily data for very long time.

To our knowledge this is the first report to provide insights on MIAVR via RAMT with the INSPIRIS RESILIA valve. Patients should benefit from less traumatic MIAVR via RAMT at first intervention and the novel INSPIRIS RESILIA aortic valve looks an appealing concept. Particularly, we report very satisfactory early-term results, and longer-term follow-up data (over 20 years) are needed to confirm our early results. Nevertheless, reducing the age for recommendation of biological valves represents a great step in the evolution of valve surgery, and enables us to track and evaluate longer-term primary data.

\section{Limitations}

This study is limited by its retrospective singlearm design and small sample size without a comparable group. It presents a performance bias as all patients were not operated on by the same surgeon, and the enrollments were not consecutive, though due only to specific inclusion/exclusion criteria. The mode of patient follow-up by email and telephone contact also introduces a risk of ascertainment bias. Therefore, the results may reflect institutional practices and not be generalizable.

Moreover, the limited number of patients in this cohort and the lack of complete size-by-size analysis of hemodynamic performance for other bioprosthesis valves are one of the main limitations of this study. Furthermore, the study focused on early postoperative hemodynamic performance, and the impact of the previously demonstrated late improvement in hemodynamic performance of bioprosthesis valves has therefore not been evaluated. For the same reason, we could not analyze the effect of the 
improved hemodynamic performance on left ventricular mass regression. The period from the diagnosis of AVD to operation for the evaluation of patients' disease severity could not be collected and analyzed because of the lack of first diagnosis date in the medical records in the majority of patients.

Finally, analysis of late outcomes was limited to 1 year of follow-up. It is limited to primary safety and efficacy at 1 year. Longer follow-up multicenter research would be required to confirm the findings of this study.

\section{CONCLUSION}

Our preliminary experience suggests that minimally RAMT for aortic valve replacement with the INSPIRIS RESILIA aortic valve can safely, effectively, and reproducibly be performed, and that the valve gives excellent hemodynamic performance. Further larger size studies are needed to evaluate the long-term efficacy and durability of the new valve.

\section{ACKNOWLEDGEMENTS}

Funding. Journal's rapid service fees and assistance in medical writing from InterComm International are supported by a research grant provided by Edwards Lifesciences SA (Nyon, Switzerland).

Authorship. All named authors meet the International Committee of Medical Journal Editors (ICME) criteria for authorship for this article, take responsibility for the integrity of the work as a whole, and have given their approval for this version to be published.

Author Contributions. Conception and design: Ali El-Sayed Ahmad; Acquisition of data: Saad Salamate, Mohamed Amer, Ömur Akhavuz; Analysis of data: Sami Sirat; Interpretation of data: Ali El-Sayed Ahmad, Sami Sirat, Farhad Bakhtiary; Drafting article: Ali El-Sayed Ahmad, Saad Salamate; Final revision the manuscript to be published: Ali El-Sayed Ahmad, Farhad Bakhtiary.

Disclosures. Farhad Bakhtiary discloses speakers' honoraria and/or consulting fees from Edwards Lifesciences, LIS and Abbott. All other authors have nothing to disclose with regard to commercial support.

Compliance with Ethics Guidelines. The study was approved by the ethics committee of the Medical Association of North Rhine, Germany (Ifd. Nr. 2019201/2019), and individual patient consent for the study was waived. The study was performed in accordance with the declaration of Helsinki 1964 and its later amendments.

Data Availability. The datasets generated and/or analyzed during the current study are available from the corresponding author on reasonable request.

Open Access. This article is licensed under a Creative Commons Attribution-NonCommercial 4.0 International License, which permits any non-commercial use, sharing, adaptation, distribution and reproduction in any medium or format, as long as you give appropriate credit to the original author(s) and the source, provide a link to the Creative Commons licence, and indicate if changes were made. The images or other third party material in this article are included in the article's Creative Commons licence, unless indicated otherwise in a credit line to the material. If material is not included in the article's Creative Commons licence and your intended use is not permitted by statutory regulation or exceeds the permitted use, you will need to obtain permission directly from the copyright holder. To view a copy of this licence, visit http:// creativecommons.org/licenses/by-nc/4.0/.

\section{REFERENCES}

1. Wang Q, Xi W, Gao Y, et al. Short-term outcomes of minimally invasive mitral valve repair: a 
propensity-matched comparison. Interact Cardiovasc Thorac Surg. 2018;26(5):805-12.

2. Thourani VH, Kodali S, Makkar RR, et al. Transcatheter aortic valve replacement versus surgical valve replacement in intermediate-risk patients: a propensity score analysis. Lancet. 2016;387(10034): 2218-25.

3. Olds A, Saadat S, Azzolini A, et al. Improved operative and recovery times with mini-thoracotomy aortic valve replacement. J Cardiothorac Surg. 2019;14(1):91.

4. Ribeiro IB, Ruel M. Right anterior minithoracotomy for aortic valve replacement: a widely applicable, simple, and stepwise approach. Innovations (Phila). 2019;14(4):321-9.

5. Del Giglio M, Mikus E, Nerla R, et al. Right anterior mini-thoracotomy vs. conventional sternotomy for aortic valve replacement: a propensity-matched comparison. J Thorac Dis. 2018;10(3):1588-95.

6. De La Fuente AB, Wright GA, Olin JM, et al. Advanced integrity preservation technology reduces bioprosthesis calcification while preserving performance and safety. J Heart Valve Dis. 2015;24(1):101-9.

7. Flameng W, Hermans H, Verbeken E, Meuris B. A randomized assessment of an advanced tissue preservation technology in the juvenile sheep model. J Thorac Cardiovasc Surg. 2015;149(1): 340-5.

8. Puskas JD, Bavaria JE, Svensson LG, et al. The COMMENCE Trial: 2-year outcomes with an aortic bioprosthesis with RESILIA tissue. Eur J Cardiothorac Surg. 2017;52(3):432-9.

9. Bartus K, Litwinowicz R, Bilewska A, et al. Intermediate-term outcomes after aortic valve replacement with a novel RESILIA ${ }^{\mathrm{TM}}$ tissue bioprosthesis. J Thorac Dis. 2019;11(7):3039-46.

10. Bartus KBA, Bochenek M, et al. Five-year outcomes of aortic valve replacement using a bioprosthetic valve with the novel RESILIA tissue: final study results. Struct Heart. 2019;3(sup1):18.

11. Johnston DR, Griffith BP, Puskas JD, Bavaria JE, Svensson LG. Intermediate-term outcomes of aortic valve replacement using a bioprosthesis with a novel tissue. J Thorac Cardiovasc Surg. 2020. https://doi.org/10.1016/j.jtcvs.2020.01.095.

12. Glauber M, Miceli A, Gilmanov D, et al. Right anterior minithoracotomy versus conventional aortic valve replacement: a propensity score matched study. J Thorac Cardiovasc Surg. 2013;145(5): 1222-6.
13. Chang C, Raza S, Altarabsheh SE, et al. Minimally invasive approaches to surgical aortic valve replacement: a meta-analysis. Ann Thorac Surg. 2018;106(6):1881-9.

14. Miceli A, Murzi M, Gilmanov D, et al. Minimally invasive aortic valve replacement using right minithoracotomy is associated with better outcomes than ministernotomy. J Thorac Cardiovasc Surg. 2014;148(1):133-7.

15. Hahn RT, Pibarot P, Stewart WJ, et al. Comparison of transcatheter and surgical aortic valve replacement in severe aortic stenosis: a longitudinal study of echocardiography parameters in cohort a of the PARTNER trial (placement of aortic transcatheter valves). J Am Coll Cardiol. 2013;61(25):2514-21.

16. Holmes DR Jr, Nishimura RA, Grover FL, et al. Annual outcomes with transcatheter valve therapy: from the STS/ACC TVT registry. Ann Thorac Surg. 2016;101(2):789-800.

17. Smith CR, Leon MB, Mack MJ, et al. Transcatheter versus surgical aortic-valve replacement in high-risk patients. N Engl J Med. 2011;364(23):2187-98.

18. Pibarot P, Borger MA, Clavel MA, et al. Study design of the prospective non-randomized single-arm multicenter evaluation of the durability of aortic bioprosthetic valves with RESILIA tissue in subjects under 65 years old (RESILIENCE trial). Structural Heart. 2020;4(1):46-52.

19. Meuris B, Borger MA, Bourguignon T, et al. Durability of bioprosthetic aortic valves in patients under the age of 60 years - rationale and design of the international INDURE registry. J Cardiothorac Surg. 2020;15(1):119.

20. Nishimura RA, Otto CM, Bonow RO, et al. 2017 AHA/ACC focused update of the 2014 AHA/ACC guideline for the management of patients with valvular heart disease: a report of the American College of Cardiology/American Heart Association task force on clinical practice guidelines. J Am Coll Cardiol. 2017;70(2):252-89.

21. Otto CM, Nishimura RA, Bonow RO, et al. 2020 ACC/AHA guideline for the management of patients with valvular heart disease: A report of the American College of Cardiology/American Heart Association joint committee on clinical practice guidelines. J Am Coll Cardiol. 2021;143(5):e35-e71.

22. Falk V, Baumgartner H, Bax JJ, et al. 2017 ESC/ EACTS guidelines for the management of valvular heart disease. Eur J Cardiothorac Surg. 2017;52(4): 616-64. 
23. Head SJ, Celik M, Kappetein AP. Mechanical versus bioprosthetic aortic valve replacement. Eur Heart J. 2017;38(28):2183-91.

24. Puvimanasinghe JP, Steyerberg EW, Takkenberg JJ, et al. Prognosis after aortic valve replacement with a bioprosthesis: predictions based on meta-analysis and microsimulation. Circulation. 2001;103(11): $1535-41$.

25. Biancari F, Valtola A, Juvonen T, et al. Trifecta versus PERIMOUNT Magna Ease aortic valve prostheses. Ann Thorac Surg. 2020;110(3):879-88.

26. Lam KY, Koene B, Timmermans N, Soliman-Hamad M, van Straten A. Reintervention after aortic valve replacement: comparison of 3 aortic bioprostheses. Ann Thorac Surg. 2020;110(2):615-21.

27. Theologou T, Harky A, Shaw M, et al. Mitroflow and PERIMOUNT Magna 10 years outcomes a direct propensity match analysis to assess reintervention rates and long follow-up mortality. J Card Surg. 2019;34(11):1279-87.

28. Bourguignon T, Bouquiaux-Stablo AL, Candolfi P, et al. Very long-term outcomes of the CarpentierEdwards PERIMOUNT valve in aortic position. Ann Thorac Surg. 2015;99(3):831-7.

29. Bourguignon T, El Khoury R, Candolfi P, et al. Very long-term outcomes of the Carpentier-Edwards
PERIMOUNT aortic valve in patients aged 60 or younger. Ann Thorac Surg. 2015;100(3):853-9.

30. al-Khaja N, Belboul A, Rashid M, et al. The influence of age on the durability of Carpentier-Edwards biological valves. Thirteen years follow-up. Eur J Cardiothorac Surg. 1991;5(12):635-40.

31. Hammermeister K, Sethi GK, Henderson WG, Grover FL, Oprian C, Rahimtoola SH. Outcomes 15 years after valve replacement with a mechanical versus a bioprosthetic valve: final report of the Veterans Affairs randomized trial. J Am Coll Cardiol. 2000;36(4):1152-8.

32. Potter DD, Sundt TM 3rd, Zehr KJ, et al. Operative risk of reoperative aortic valve replacement. J Thorac Cardiovasc Surg. 2005;129(1):94-103.

33. LaPar DJ, Yang Z, Stukenborg GJ, et al. Outcomes of reoperative aortic valve replacement after previous sternotomy. J Thorac Cardiovasc Surg. 2010;139(2): 263-72.

34. Chan V, Malas T, Lapierre H, et al. Reoperation of left heart valve bioprostheses according to age at implantation. Circulation. 2011;124(11 Suppl):S75-80.

35. Milewski RK, Habertheuer A, Bavaria JE, et al. Selection of prosthetic aortic valve and root replacement in patients younger than age 30 years. J Thorac Cardiovasc Surg. 2019;157(2):714-25. 